\title{
Development of the International Spinal Cord Injury/Dysfunction Education Basic Data Set
}

\author{
Joan Carney ${ }^{1} \cdot$ Rhona Fisher $^{2} \cdot$ Marika Augutis $^{3} \cdot$ Susan Charlifue $^{4} \cdot$ Fin Biering-Sørensen ${ }^{5} \cdot$ Wiebke Höfers $^{6}$.

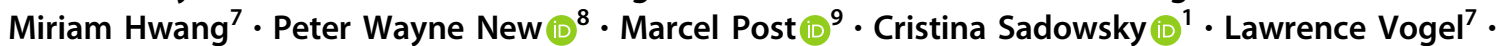 \\ Lilly Augustine $^{10} \cdot$ Kathryn Dent $^{11} \cdot$ M. J. Mulcahey $\mathbb{D}^{11}$
}

Received: 21 January 2019 / Revised: 2 August 2019 / Accepted: 11 August 2019

(C) The Author(s), under exclusive licence to International Spinal Cord Society 2019

\begin{abstract}
Study design Consensus among international experts.

Objectives The objective of this project was to develop the International Spinal Cord Injury/Dysfunction (SCI/D) Education Basic Data Set.

Setting International expert working group.

Methods The published guidelines for developing the International SCI Basic Data Sets were used to develop the International SCI/D Education Basic Data Set. Existing measures and literature on education and disability were reviewed to develop a preliminary draft of the basic education data set through iterative modifications via biweekly conference calls and email communication. The draft was disseminated to the larger International Workgroup for Development of Pediatric SCI/ D Basic Data Sets and then to the members of the International Spinal Cord Society (ISCoS), American Spinal Injury Association (ASIA), and relevant expert groups and interested individuals for comments. All feedback received was taken into consideration before the final data set was approved by ISCoS and ASIA.

Results The finalized version of the International SCI/D Education Basic Data Set Version 1.0 contains 16 items divided into three domains: school setting/therapeutic services, school participation/academic success, and barriers/attitudes. Most of the variables have been adapted from established measures. This data set is intended for children and youth up to and including high school, but not for emerging adults in higher education or postsecondary vocational training or trade schools. Conclusion The International SCI/D Education Basic Data Set has been developed for collection of a minimal amount of highly relevant information on the education experience in children and youth with SCI/D. Further validation work is needed. Sponsorship This project was funded by the Rick Hansen Institute, Research Award \#G2015-27 (Mulcahey, PI).
\end{abstract}

Supplementary information The online version of this article (https:// doi.org/10.1038/s41394-019-0229-1) contains supplementary material, which is available to authorized users.

$\triangle$ M. J. Mulcahey

maryjane.mulcahey@jefferson.edu

1 Rehabilitation Department, Kennedy Krieger Rehabilitation Institute, Baltimore, MD, USA

2 Fisher Association, Baltimore, MD, USA

3 Department of Neurobiology, Care Sciences and Society, Karolinska Institute, Stockholm, Sweden

4 Research Department, Craig Hospital, Englewood, CO, USA

5 Department of Spinal Cord Injuries, Neuroscience Centre, Rigshospitalet, University of Copenhagen, Copenhagen, Denmark

6 Physiotherapy Department, Sunnaas Hospital, Bjørnemyr, Norway

7 Research Department, Shriners Hospitals for Children,
Chicago, IL, USA

8 Epworth-Monash Rehabilitation Unit, Department of Epidemilogy and Preventitive Medicine, School of Public Health and Preventative Medicine, Monash University, Melbourne, Australia

9 Center of Excellence for Rehabilitation Medicine, Brain Center Rudolf Magnus, University Utrecht and De Hoogstraat Rehabilitation, Utrecht, Netherlands

10 School of Education and Psychology, Jönköping University, Jönköping, Sweden

11 Department of Occupational Therapy, Center for Outcomes and Measurement, Jefferson College of Rehabilitation Sciences, Jefferson (Philadelphia University+Thomas Jefferson University), Philadelphia, PA, USA 


\section{Introduction}

Educational programs constitute a major aspect of all school-aged children's lives. Achievement in education plays a crucial role in an individual's employability, social development, and potential for independent living [1-4]. Education predicts socioeconomic status, and higher degrees of education correlate strongly with healthier lifestyles, better living conditions, and accessibility to care $[5,6]$.

Sustaining a spinal cord injury (SCI) or spinal cord damage (SCD) due to traumatic or nontraumatic events or diseases can have serious implications on a child's general development and overall well-being [4, 7-9]. There are other contributing factors such as social class and country of origin, but in many instances children with chronic impairments, such as SCI/D are at risk for falling behind in education and failing to meet their educational potential [9]. Certain provisions and standards must be employed to ensure proper educational programming and reentry into the school system for children with SCI/D [9]. Continuous assessments of and modifications to educational programs for individuals with SCI/D are necessary to ensure minimal barriers to and maximum possibility of success at school [10]. Notably, educational programming for the student with SCI/D-related impairments can also be complicated by a student's preinjury cognitive profile or a co-occurring traumatic brain injury [11-14].

The International SCI/D Education Basic Data Set was first conceptualized after gaps identified in the existing International SCI Basic Data Sets for children and youth with SCI $[15,16]$. Although other International SCI Basic Data Sets provide standardization for collection and recording of physical and medical variables important to SCI care, pediatric interdisciplinary care teams also include assessment of education status into routine evaluations and longitudinal monitoring, owing to the central role school and education have on children's everyday living and long-term outcomes. The purpose of the International SCI/D Education Basic Data Set is to standardize the collection and reporting of the minimum amount of information considered highly relevant to the educational experience of children and youth with SCI/D.

\section{Methods for development}

The international SCI/D Education Basic Data Set was created by an interdisciplinary working group of experts in education, and in pediatric and adult SCI/D rehabilitation and rehabilitation research. Data Set development followed the general guidelines described by BieringSørensen et al. [17] and followed an iterative process described below.

(1) The working group reviewed existing literature and measures for education and education in relation to children and adolescents with disabilities, including SCIs [10, 18-27].

(2) Existing instruments, surveys, The National Institute Neurological Diseases and Stroke (NINDS) SCI common data elements, proceedings and studies [28-37] that contained school and education related items were examined to create a preliminary draft of the data set.

(3) The group reviewed iterative drafts of the data set via biweekly conference calls and frequent email communications over a 1-year period (2017-2018).

(4) A full draft was vetted during a face-to-face meeting of the larger Workgroup for Development of Pediatric SCI/D Basic Data Sets, held in Philadelphia PA.

(5) The International SCI/D Data Sets Committee as asked to review the draft. No additional suggestions or comments were made.

(6) The draft was sent to the American Spinal Injury Association (ASIA) Board and the International Spinal Cord Society (ISCoS) with a request to make the draft available on the respective websites for membership feedback. No additional suggestions or comments were made.

(7) The draft was sent to national and international organizations and several interested individuals, feedback was integrated.

(8) The International SCI/D Education Basic Data Set approved by ASIA Board and the ISCoS.

\section{Results}

The International SCI/D Education Basic Data Set Version 1.0 contains 16 items that are considered highly relevant to the educational experience of children and adolescents with SCI/D. The variables are classified into one of three domains: school setting/therapeutic services, school participation/academic success, and barriers/attitudes. The domains reflect those that are discussed in the literature $[10,21,22,27,30,34]$. Many of the variables have been taken or adapted from existing instruments or forms [2830, 33-37] that are used for educational assessment. Only items that were considered internationally relevant were included in the basic data set.

Presented below are the International SCI/D Education Basic Data Set variables and associated descriptions. 


\section{Date of data collection}

As the collection of data on the educational experience of individuals with SCI/D may take place any time after discharge from initial acute rehabilitation, the standardized collecting and coding of collection date is vital to assess longitudinal changes and progress in the education experience. This allows educational data collected at any given time point to be assessed in conjunction with relevant physiological, rehabilitation, and/or psychosocial data collected at the same time.

\section{Years of formal education completed}

This variable documents the year of formal education completed starting at 5 years of age. The intent of this variable is to determine the level of education and provide a context for the remaining items in the data set. This variable is taken from the NINDS SCI demographic CDE form [37].

\section{Educational setting}

This variable captures the current educational setting. Regular education refers to an inclusive educational setting, where students with SCI/D are educated with peers with and/or without disabilities, and are provided with additional resources and support to function within the typical classroom and school environment, as needed. Integrated education refers to the offering of separate classes and additional resources for students with SCI/D within the typical school environment. Special education is defined as a segregated educational setting for students with special needs. In this setting, schools provide specialized services in separate classroom settings from typical mainstream educational institutions. Home schooling and/or hospital school means that the individual receives education in the home or hospital setting, which may also include online and internet-accessed instructions. If the individual undergoes home schooling and/or schooling in the hospital setting, they should not continue to fill out the rest of the International SCI/D Education Data Set because it is only applicable to students receiving education outside of the home or hospital. Definitions are based in part on the World Report on Disability by the World Health Organization [27] and The Special Education Guide Dictionary of Terms [38].

\section{Therapeutic services}

This variable documents therapeutic services that are utilized within the past 4 weeks of consistent (uninterrupted by prolonged absences) attendance in the given educational setting. A medical care attendant is a licensed/skilled care provider such as a nurse, nurse's aide, etc., who provides medical care related to the SCI/D. Physical therapy is the provision of skilled therapy on the use of therapeutic exercise, mobility training, and education for the preservation, enhancement or restoration of movement and physical function needed to support school participation. Occupational therapy is the provision of skilled therapy for purposes of maintaining or improving performance of activities that are required and desired for competency within the classroom and school environment. Speech/language therapy is the provision of skilled therapy to support needs associated with communicating and swallowing safely. Counseling/mental health is the provision of assistance and guidance by a trained professional in resolving personal, social, and/or psychological problems and difficulties. Social work/case management is work carried out by trained personnel with the aim of alleviating the conditions of those needing help or welfare. Adapted physical education is the instruction of physical education and games provided in school by a trained educator that has been adapted to the abilities of those who could not participate otherwise. Vocational services are services that are focused on work, vocation, and transition into adult work or educational environments and can be provided by a vocational counselor, educator, occupational therapist, counselor, social work, or a combination of two or more of these disciplines.

\section{School days missed due to spinal cord injury/ dysfunction}

The variable documents if the child has been absent 5 or more days of school during the past 4 weeks due to health related issues, whether directly or indirectly caused by the SCI/D. Youth with disabilities or learning differences have a high rate of absenteeism [10]. Missing more than 5 days of school in a 4 week period may indicate serious health issues and/or issues specific to willingness or ability to regularly attend school. In rare cases, high absenteeism may indicate that appropriate educational programs and/or services are not available for that student.

\section{Student's current academic performance}

This variable documents the student's self-perceived overall academic performance in comparison to classmates (peers at the same level of education). Students describe their performance as one of the following: (1) doing at least as well as classmates in all academic or course subjects; (2) not doing as well as classmates in some academic or course subjects; or (3) not doing as well as classmates in all academic or course subjects. This information can be used to examine the success of the educational program and the student's confidence in their academic abilities. 


\section{School activities}

The following four items were drawn from the Pediatric Measure of Participation (PMoP) [28]. The codes for these variables describe whether or not the student participates in the school activity, and the degree to which they do so based on their desire to engage as coded as one of the following: "I don't do it"; "I do it a lot less than I want"; "I do it a little less than I want"; "I do it as much as I want". A student's response of "I don't do it" is not necessarily due to physical limitations or a lack of desire, but could indicate that the student is not allowed to participate, does not have access to participate, or another reason or a combination of two or more reasons. Together, the variables obtained from the PMoP provide information about school related social, play, and recreation within the educational setting. Items on the PMoP were developed through iterative focus groups and interviews, and identified as highly important and relevant by children and adolescents with SCI/D [39, 40].

\section{Eating with friends/classmates}

This variable documents whether or not the individual eats lunch with friends/classmates during school, and the degree to which they do it based on how much they want to do it.

\section{Participation in school (field) trips}

This variable documents participation in school (field) trips with friends/classmates and the degree to which they do it based on how much they want to participate in them.

\section{Participation in physical education activities}

This variable documents participation in gym class (physical education or formal school-arranged sporting activities) and the degree to which they do it based on how much they want to do it.

\section{Participation in recess}

This variable documents participation in recess or time allocated for recreational play with classmates during the school day and the degree to which they do it based on how much they want to do it.

\section{Physical/environmental barriers}

The following five items have been adapted from the Nottwil Environmental Factors Inventory-Short Form [29]. This SCI-specific instrument emphasizes the self-perceived impact of environmental barriers on overall participation. The barriers to accessibility are coded as follows: (1) has no influence; (2) makes school a little harder; (3) makes school a lot harder or (4) unknown.

\section{Barriers to school access}

This variable documents accessibility within the school building.

\section{Barriers to transportation to and from school}

This variable documents adequate transportation to and from school.

\section{Barriers to communication devices at school}

This variable documents accessibility to adequate communication devices such as writing devices, voice recognition software, and other assistive or computer devices.

\section{Barriers to other educational supports at school}

This variable documents accessibility to education supports such as personal assistant, computer access, or modifications within the school curriculum.

\section{Attitudes of educational professionals}

This variable documents the impact of the individual's perception of possible negative attitudes of school staff.

\section{Perception of school}

This variable documents the individuals' feeling toward school in general. This item has been adapted from the Health Behavior in School-Aged Children (HBSC) $[30,33,34]$. The HBSC survey is utilized in over 40 countries in an effort to systematically collect data and draw cross-national comparisons regarding the health, social environments, and health behaviors of school-age children [35].

\section{Discussion}

Prior to the development of the International SCI/D Education Basic Data Set there has been no uniform method to systematically document the educational experience of students with SCI/D. The International SCI/D Basic Education Data Set was developed through a formal iterative process using established guidelines [17]. During the development of this data set, international differences in educational programs, grade levels, and educational terminology were recognized, and only variables that were 
considered globally applicable were retained. The data set would benefit from field testing for cultural validation, reliability, feasibility, and relevance. It is important to note that there were many more variables that were considered highly relevant and globally applicable that were not retained for the basic data set. Keeping with the spirit of the concept of a "basic data set" (i.e., fewest question, low burden), we eliminated variables for the basic data set but recorded them for future development of an extended education data set.

The International SCI/D Education Basic Data Set is intended for use with school-aged individuals who are at least 6 years of age and who are discharged from initial acute rehabilitation. The variables on the data set are relevant to children and youth through to completion of high school, but not to emerging adults in higher (college/university) or postsecondary vocational education. Administration of the data set is by way of interview to the student, engaging the parent/caregiver as appropriate. The parent/ caregiver may complete items describing the educational program and number of school days missed, and the student with SCI/D should respond to items regarding current academic performance, educational participation, barriers to education, attitudes of educational professionals, and perception of school. Other pediatric data sets in development provide information on independence in self-care and mobility, and the frequency of participation in activities outside of school. Those who administer the International SCI/D Education Basic Data Set may want to consider using these additional data sets as they become available.

The International SCI/D Education Basic Data Set has the potential to be used in both wider health care and educational environments. For example, it can be utilized as a tool during the educational referral process, educational planning, and monitoring process. While it is not a standardized evaluation tool, it may aide in the overall understanding of school experience by children with SCI/D. Until further validation, it is not recommended for research.

\section{Conclusion}

The International SCI/D Education Basic Data Set was designed to standardize the collection of a minimal number of variables for monitoring educational experience after pediatric SCI/D. We recommend that the data set be exposed to validation studies. Translation, if performed, should be conducted in accordance with the protocols outlined for all International SCI Data Sets [41].

Acknowledgements The following are acknowledged for their contributions to the development of this data set: Andrea Behrman PhD, Michael J. DeVivo DrPH, Linda Jones MSPT, Carol Haywood OTR/L,
PhD, Bethany Lipa MD, Rebecca Martin OTR, Vanessa Noonan PhD, Kathy Zebracki $\mathrm{PhD}$, and individuals who provided feedback in anonymity as part of the public review process.

Conflict of interest At the time of this study, MJM received research support from the Shiners Hospitals for Children, National Institute Neurological Disease and Stroke, The Craig H. Neilsen Foundation and The Rick Hansen Institute. She receives compensation for her role as Associate Editor for Topics in Spinal Cord Rehabilitation, royalties for the text book "The Child and Young Adult with Spinal Cord Injury." LV receives compensation for his role as Editor for Topics in Spinal Cord Rehabilitation, royalties for the text book "The Child and Young Adult with Spinal Cord Injury. The remaining authors declare no conflict of interest.

Ethics statement All the authors affirm that the paper is an authentic, accurate, and transparent account of the project; no aspects of the project have been omitted. This project did not involve review of deidentified data and did not involve human subjects, and therefore did not meet the requirements for human subject research.

Publisher's note Springer Nature remains neutral with regard to jurisdictional claims in published maps and institutional affiliations.

\section{References}

1. Bedell G, Coster W. Measuring participation of school-aged children with traumatic brain injuries: considerations and approaches. J Head Trauma Rehabil. 2008;23:220-9.

2. Anderson CJ, Vogel LC. Employment outcomes of adults who sustained spinal cord injuries as children or adolescents. Arch Phys Med Rehabil. 2002;83:791-801.

3. Whiteneck G, Tate D, Charlifue S. Predicting community reintegration after spinal cord injury from demographic and injury characteristics. Arch Phys Med Rehabil. 1999;80:1485-91.

4. Krause JS, Anson CA. Employment after spinal cord injury: relation to selected participant characteristics. Arch Phys Med Rehabil. 1996;77:737-43.

5. Zimmerman EB, Woolf SH, Haley A. Understanding the relationship between education and health: a review of the evidence and an examination of community perspectives. In Kaplan R, Spittel M, David D. Population Health: Behavioral and Social Science Insights. AHRQ Publication No. 15-0002. Rockville, MD: Agency for Healthcare Research and Quality and Office of Behavioral and Social Sciences Research. National Institutes of Health 2015;347-84.

6. Trenaman L, Miller WC, Queree M, Escorpizo R, SCIRE Research Team. Modifiable and non-modifiable factors associated with employment outcomes following spinal cord injury: a systematic review. J Spinal Cord Med. 2015;38:422-31.

7. Massagli TL, Dudgeon BJ, Ross BW. Educational performance and vocational participation after spinal cord injury in childhood. Arch Phys Med Rehabil. 1996;77:995-9.

8. Lum A, Wakefield CE, Donnan B, Burns MA, Fardell JE, Marshall GM. Understanding the school experiences of children and adolescents with serious chronic illness: a systematic review. Child Care Health Dev. 2017;43:645-62.

9. Knight A, Petrie P, Potts P, Zuurmond M. The school lives of children and young people with spinal cord injury. Institute of Education, University of London; 2008. Downloaded from: http:// researchonline.1shtm.ac.uk/3599/.

10. Garcia E, Weiss E. Student absenteeism. Who misses school and how missing school matters for performance. Washington, DC: Economic Policy Institute; 2018. 
11. Macciocchi S, Seel R, Thopmson N, Byams R, Bowman B. Spinal cord injury and co-occcuring traumatic brain injury: assessment and incidence. Arch Phys Med Rehabil. 2008;89:1350-7.

12. Kushner D, Alvarez G. Dual diagnosis: traumatic brain injury with spinal cord injury. Phys Med Rehabil Clin N Am. 2014;25:681-96.

13. Ghobrial GM, Amenta PS, Maltenfort M, Williams KA Jr, Harrop JS, Sharan A, et al. Longitudinal incidence and concurrence rates for traumatic brain injury and spine injury-a twenty year analysis. Clin Neurol Neurosurg. 2014;123:174-80.

14. Sanford P, Falk-Palec D, Spears K. Return to school after spinal cord injury. Arch Phys Med Rehabil. 1999;80:855-88.

15. Carroll A, Vogel LC, Zebracki K, Noonan VK, Biering-Sørensen F, Mulcahey MJ. Relevance of the international spinal cord injury basic data sets to youth: an inter-professional review with recommendations. Spinal Cord. 2017;55:875-81. https://doi.org/ $10.1038 / \mathrm{sc} .2017 .14$

16. Mulcahey MJ, Vogel LC, Sheikh M, Arango-Lasprilla JC, Augutis M, Garner E, et al. Recommendations for the National Institute for Neurologic Disorders and Stroke spinal cord injury common data elements for children and youth with SCI. Spinal Cord. 2017;55:331-40.

17. Biering-Sørensen F, Charlifue S, DeVivo M, Noonan V, Post M, Stripling $\mathrm{T}$, et al. International Spinal Cord Injury Data Sets. Spinal Cord. 2006;44:530-4.

18. Thies KM. Identifying the educational implications of chronic illness in school children. J Sch Health. 1999;69:392-7.

19. Sentenac M, Ehlinger V, Michelsen SI, Marcelli M, Dickinson HO, Arnaud C. Determinants of inclusive education of 8-12 year old children with cerebral palsy in 9 European regions. Res Dev Disabil. 2013;34:588-95.

20. Lum A, Wakefield CE, Donnan B, Burns MA, Fardell JE, Marshall GM. Understanding the school experience of children and adolescents with serious chronic illness: a systematic metareview. Child Care Health Dev. 2017. https://doi.org/10.1111/ cch12475.

21. Forrest CB, Berans KB, Riley AW, Crespo R, Louis TA. School outcomes of children with special health care needs. Pediatrics. 2011;128:303-12. https://doi.org/10.1542/peds.2010-3347.

22. Boonen H, Petry K. How do children with a chronic or long-term illness perceived their school re-entry after a period of homebound instruction? Child Care Health Dev. 2011;38:490-6. https://doi. org/10.1111/j.1365-2214.2011.01279.x.

23. Dumas HM, Bedell GM, Hamill MS. Strategies to promote activity and participation in children and youths with acquired brain injuries. Int J Rehabil Research. 2003;26:303-8.

24. Education 2030. Incheon declaration: towards inclusive and equitable quality education and lifelong learning for all. www. unesco.org/new/fileadmin/multimedia/HQ/ED/ED_new/pdf/.

25. UNESCO Institute for Statistics. International Standard Classification of Education. Montreal CA: UNESCO Institute for Statistics; 2011. https://www.uis.unesco.orgref:uis/2012/INS/10/REV.

26. Dept. of Education and Training. Inclusive education for all students with disabilities and additional needs. The government's response to the review of the program for students with disabilities. Melbourne: Dept. of Education and Training; 2016.

27. World Health Organization. World Report on Disability. World Health Organization; 2011. https://www.who.int/disabilities/w orld_report/2011/en/.

28. Mulcahey MJ, Slavin MD, Ni P, Vogel LC, Thielen CC, Coster WJ, et al. The Pediatric Measure of Participation (PMoP) short forms. Spinal Cord. 2016;54:1183-7.

29. Ballert CS, Post MW, Brinkhof MW, Reinhardt JD, SwiSCI Study Group. Psychometric properties of the Nottwil Environmental Factors Inventory Short Form. Arch Phys Med Rehabil. 2015;96:233-40.

30. Currie C, Inchley J, Molcho M, Lenzi M, Veselska Z, Wild F, editors. Health behaviour in school-aged children (HBSC) study protocol: background, methodology and mandatory items for the 2013/14 survey. Child and Adolescent Health Research Unit (CAHRU), University of St Andrews; 2014.

31. Sandford PR, Falk-Palec DJ, Spears K. Return to school after spinal cord injury. Arch Phys Med Rehabil. 1999;80:885-8.

32. Mulcahey MJ. Returning to school after spinal cord injury: perspective from adolescents. Am J Occup Ther. 1992;46:305-12.

33. Schnohr CW, Molcho M, Rasmussen M, Samdal O, de Looze M, Levin $\mathrm{K}$, et al. Trend analyses in the health behaviour in schoolaged children study: methodological considerations and recommendations. Eur J Public Health. 2015;25(Suppl 2):7-12.

34. Curie C, van der Sluijs W, Whitehead R, Currie D, Rhodes G, Neville F, et al. HBSC 2014 survey in scotland national report. Child and adolescent health research unit (CAHRU), University of St Andrews; 2015.

35. HBSC International Coordinating Centre Child \& Adolescent Health Research Unit. About HBSC. http://www.hbsc.org/about/ index.html.

36. Coster W, Deeney T, Haltiwanger J, Haley S. School function assessment user's manual. San Antoni, TX: The Psychological Corp./Therapy SkillsBuilder; 1998.

37. Biering-Sørensen F, Alai S, Anderson K, Charlifue S, Chen Y, DeVivo $\mathrm{M}$, et al. Common data elements for spinal cord injury clinical research: a National Institute for Neurological Disorders and Stroke project. Spinal Cord. 2015;53:265-77.

38. Special Education Guide. Special education dictionary. Washington DC: Special Education Guide. https://www.specia leducationguide.com/special-education-dictionary/.

39. Calhoun CL, Haley SM, Riley A, Vogel LC, McDonald CM, Mulcahey MJ. Development of items designed to evaluate activity performance and participation in children and adolescents with spinal cord injury. Int J Pediatr. 2009:854904.

40. Mulcahey MJ, DiGiovanni N, Calhoun C, Homko E, Riley A, Haley S. Children's and parents' perspectives of activity performance and participation following spinal cord injury. Am J Occup Ther. 2010;64:605-13.

41. Biering-Sørensen F, Alexander MS, Burns S, Charlifue S, DeVivo $\mathrm{M}$, Dietz V, et al. Recommendations for translation and reliability testing if the International Spinal Cord Injury Data Sets. Spinal Cord. 2011;49:357-60. 